Relationships Between Landscape Habitat

Characteristics and Relative Density Categories of

Steelhead Trout and Chinook Salmon Parr in Idaho

Annual Report 1999

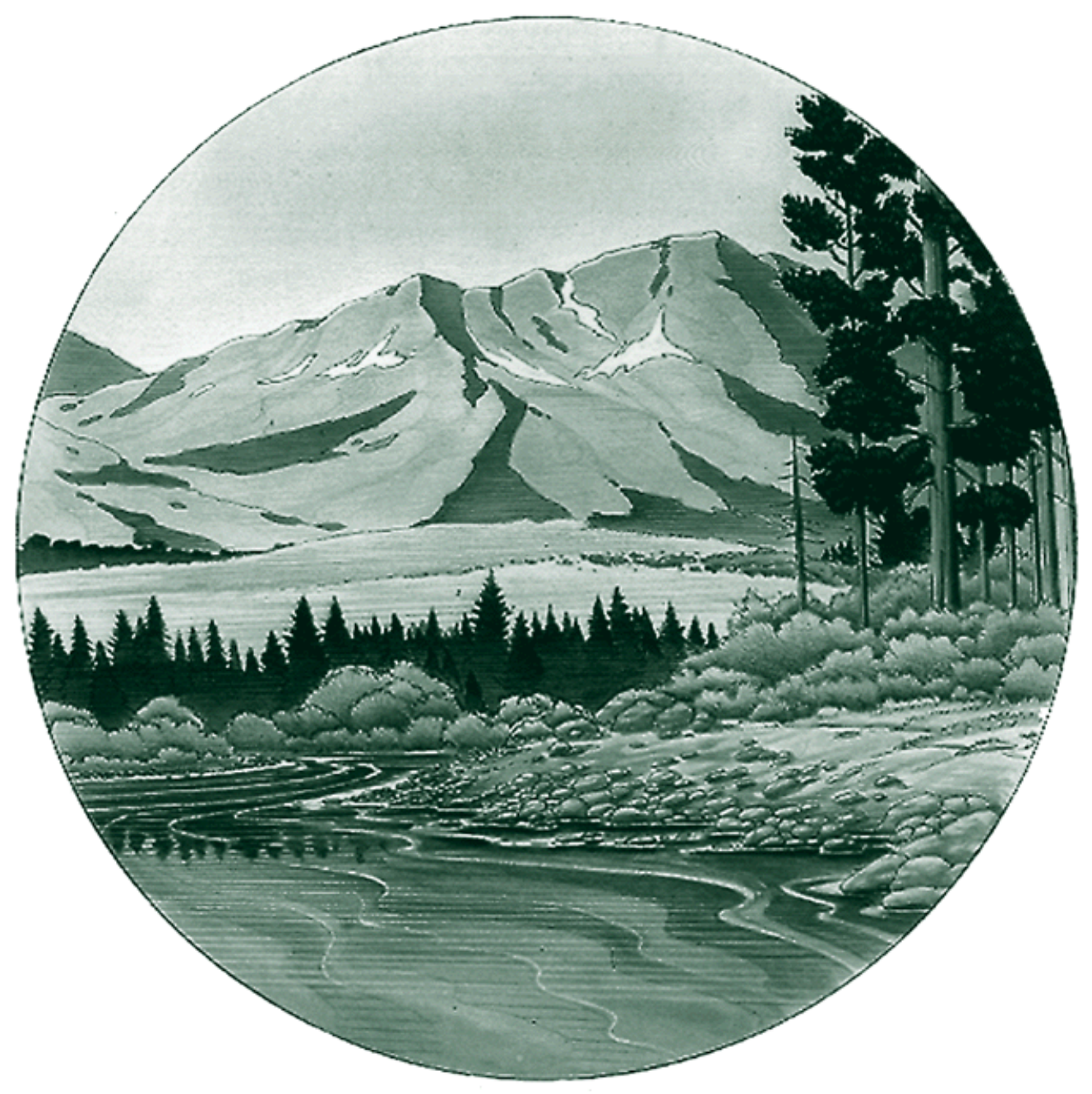

DOE/BP-25866-5 
This report was funded by the Bonneville Power Administration (BPA), U.S. Department of Energy, as part of BPA's program to protect, mitigate, and enhance fish and wildlife affected by the development and operation of hydroelectric facilities on the Columbia River and its tributaries. The views of this report are the author's and do not necessarily represent the views of BPA.

This document should be cited as follows:

Thompson, William L., D. C. Lee, U. S. Dept. of Agriculture Forest Service, 1999, Relationships Between Landscape Habitat Characteristics and Relative Density Categories of Steelhead Trout and Chinook Salmon Parr in Idaho,

Annual Report 1999 to Bonneville Power Administration, Portland, OR, Contract No. 92AI25866, Project No.

92-032-00, 17 electronic pages (BPA Report DOE/BP-25866-5)

This report and other BPA Fish and Wildlife Publications are available on the Internet at:

\section{http://www.efw.bpa.gov/cgi-bin/efw/FW/publications.cgi}

For other information on electronic documents or other printed media, contact or write to:

Bonneville Power Administration Environment, Fish and Wildlife Division

P.O. Box 3621

905 N.E. 11th Avenue

Portland, OR 97208-3621

Please include title, author, and DOE/BP number in the request. 


\title{
Relationships Between Landscape Habitat Characteristics and Relative Density Categories of Steelhead Trout and Chinook Salmon Parr in Idaho
}

\author{
Prepared by: \\ William L. Thompson \\ and \\ Danny C. Lee ${ }^{1}$ \\ U.S. Department of Agriculture Forest Service, \\ Rocky Mountain Research Station, Boise, Idaho
}

Prepared for:

\author{
U.S. Department of Energy \\ Bonneville Power Administration \\ Environment, Fish and Wildlife \\ P.O. Box 3621 \\ Portland, OR 97208-3621 \\ Project Number 92-032-00 \\ Contract Number 92AI25866
}

September 1999

\footnotetext{
${ }^{1}$ Current address: U.S.D.A. Forest Service, Sierra Nevada Conservation Framework, 801 I Street, Sacramento, CA 95814.
} 


\section{Introduction}

Numbers of anadromous salmonids have greatly decreased from previously recorded levels for many stocks in the northwestern United States (Nehlsen et al. 1991). For instance, numbers of salmon and steelhead trout (Oncorhynchus mykiss) in the Columbia River Basin have plummeted from an estimated 10-16 million adults to about 1.5-4 million adults during this century (Northwest Power Planning Council 1986). Factors thought to be driving these declines include deleterious effects of hydroelectric dams on upstream access and downstream passage, loss or degradation of freshwater spawning and rearing habitats, overexploitation by commercial fisheries, and detrimental impacts of hatchery fish on wild populations (Nehlsen et al. 1991, National Research Council 1996, Lee et al. 1997). Efforts to ensure long-term persistence of these populations are hampered by conflicts with local socioeconomic interests, and uncertainties associated with complex life history patterns of anadromous salmonids (Bisson et al. 1992) and with the overall system (Lee and Grant 1995).

A cooperative effort is currently underway by scientists from various state, federal, tribal, and private agencies to construct a formal decision analysis for evaluating different management alternatives for restoring threatened and endangered stocks of steelhead, fall chinook, and spring/summer chinook in the Columbia River Basin; this effort is called PATH (Plan for Analyzing and Testing Hypotheses) (Marmorek and Peters 1998). An especially challenging aspect of the PATH process is to identify and, when possible, resolve sources of uncertainty associated with the complex life cycle of anadromous salmonids in the Basin. The PATH group has categorized these sources as hydrosystem, habitat, harvest, hatcheries, and climate (Marmorek and Peters 1998). Hydrosystem options have received the majority of focus to date, and hence there is a need for an investigation into the influence of other factors, such as freshwater rearing habitat, on numbers of anadromous salmonids. Further, an emphasis on a landscape or basinwide level approach is necessary to properly evaluate possible influences of habitat factors on numbers of anadromous salmonids in their rearing environments (Schlosser 1991, Roper et al. 1994). To our knowledge, there are no published articles assessing these relationships on a landscape scale in the Columbia River Basin.

In this paper, we investigate possible relationships between landscape habitat characteristics and density categories of steelhead trout and spring/summer chinook (Oncorhynchus tshawytscha) parr within index streams in the Snake River drainage in Idaho. This geographical area is of particular importance because Snake River stocks of steelhead trout and spring/summer chinook salmon have been listed as threatened under the Endangered Species Act (Federal Register 1997, 1998a). This paper is part of the ongoing PATH process that is evaluating the importance of various factors potentially affecting the persistence of anadromous salmonid stocks in the Columbia River Basin. 


\section{Methods}

\section{General Parr Monitoring Program}

The Idaho Department of Fish and Game (IDFG) and several cooperating agencies have been surveying numbers of juvenile steelhead trout and chinook salmon in the Salmon, Clearwater, and lower Snake River drainages in Idaho since 1984 (HallGriswold and Petrosky 1996). These drainages contain nearly all of the wild and naturally-producing steelhead trout and chinook salmon in Idaho (Petrosky and Holubetz 1986). Originally, a primary objective of these surveys was to assess effects of various habitat mitigation actions on local numbers of steelhead and chinook parr. Some stream sections were stocked with hatchery fish to better evaluate population responses of parr to mitigation measures (Petrosky and Holubetz 1986). Since the early 1990's, however, long-term monitoring of parr numbers has been the primary focus (C. Petrosky, pers. commun.). Results of these surveys have been incorporated into a single database by IDFG personnel.

The following is a summary of the sampling protocol used to generate data contained within the general parr monitoring database. Indices of relative abundance were obtained via snorkel counts by divers swimming approximately $100 \mathrm{~m}$ upstream within stream sections. One to five or more divers were used depending on stream size (see Petrosky and Holubetz 1986 for a more detailed description of snorkel counts). Stream sections were chosen based on a variety of reasons such as access, existence of previous counts, perceived quality of rearing habitat, etc. (J. Hall-Griswold, pers. commun.). Thus, selection of stream sections was nonrandom, but they represented a spectrum of habitats, stocks, and production types (i.e., wild [native] and natural [having a previous hatchery influence]; Rich and Petrosky 1994). Although an attempt was made to survey the same sections over time, location and size of snorkeled sections often varied across years mainly due to loss of previous section boundary markers, difficulties in relocating inadequately described sections, loss of access, and annual differences in stream flows. Further, not all sections were surveyed every year because of manpower, funding, and logistical constraints (J. Hall-Griswold, pers. commun.). In addition, a stream prioritization plan was implemented in 1995 that defined the annual frequency at which different stream sections would be snorkeled (Hall-Griswold and Petrosky 1996).

\section{Subsetting the Data}

We only analyzed counts from stream sections where mitigation measures and stocking were not applied (see Rich and Petrosky 1994:Appendix B) because of their confounding effects on the relationship between habitat and fish numbers. Also, we limited our analyses to counts conducted when the water temperature exceeded $9{ }^{\circ} \mathrm{C}$ because of the low detectability of fish below this temperature (Thurow 1994). Further, only count data collected during 1986-1995 were considered for our analyses because these data had been verified for input accuracy in the IDFG database (Hall-Griswold and Petrosky 1996). 
Counts were divided by the estimated area of each snorkeled stream section to convert them into density indices. Because these snorkel counts were uncorrected for incomplete detectability of fish and therefore contained an unknown amount of bias (Thompson et al. 1998), we pooled density indices into two categories in attempt to alleviate effects of this bias. Specifically, we defined these categories as: 1) parr absent or at low densities and 2) parr at moderate to high densities. Low density values for both species were defined based on fish density/habitat ratings used by IDFG to categorize quality of rearing habitat; these values were $0.06 \mathrm{parr} / \mathrm{m}^{2}$ for steelhead and $0.12 \mathrm{parr} / \mathrm{m}^{2}$ for chinook (Hall-Griswold and Petrosky 1996). Thus, observed parr densities at or below $0.06 / \mathrm{m}^{2}$ for steelhead or $0.12 / \mathrm{m}^{2}$ for chinook were placed in category 1 , whereas higher observed densities were placed in category 2 .

We pooled A and B runs for steelhead, and spring and summer runs for chinook because sample sizes were inadequate to model these data separately. Although peaks in average relative densities differed slightly between $A$ and $B$ runs for both species in a couple of years during 1986-1990, their 90\% confidence interval broadly overlapped. We also included both wild and natural populations in our analyses. Further, we concentrated on counts from B channels (Rosgen 1985) for steelhead and C channels for chinook because these are their preferred habitats (Hall-Griswold and Petrosky 1996) and therefore should support higher densities of parr. Finally, data from the year with the highest average observed density for each species were used in our investigation of landscape linkages. We did this to maximize our ability to detect a difference between high and low quality sites. Preliminary analyses suggested that average relative densities of fish were similar between better quality sites and lower quality sites during years of low numbers, whereas there was a distinct difference between these sites during years of high numbers (J. Peterson, pers. commun.). Difficulties associated with site identification, nonrandom site selection, incomplete time series of surveys, and counting bias precluded use of typical approaches for modeling time series data.

\section{Modeling Approach}

We employed the basic approach to model building and selection suggested by Akaike (1973) and further explained by Burnham and Anderson (1998). First, we constructed a global logistic regression model with density categories as the dichotomous response (see above) and landscape-level habitat covariates that we deemed biologically most relevant as predictors. Landscape habitat data were compiled by Lee et al. (1997) at the subwatershed level of spatial scale $\left(6^{\text {th }}\right.$ field Hydrologic Unit Code [HUC6]), which is about 7,800 ha on average within the Columbia Basin, and were generally categorized as physiographic and geophysical or anthropogenic (Table 1).

We then assessed the fit of the global model via the Hosmer-Lemeshow goodness-of-fit (GOF) test and checked the Pearson $\chi^{2}$ residuals for obvious outliers (Hosmer and Lemeshow 1989). The Hosmer-Lemeshow GOF statistic is generated by ordering observations by their event probabilities, grouping them into a $2 \times g$ table (where $g$ is number of groups; see Hosmer and Lemeshow 1989 for the grouping 
procedure), and calculating a Pearson $\chi^{2}$ GOF statistic for this table. Small $P$-values indicate model lack of fit. If the global model adequately fits the data, we constructed a subset of candidate models from it that represented biologically meaningful combinations of the landscape covariates. Each subsetted model was assumed to provide an adequate fit if the global model did so (Burnham and Anderson 1998).

Model selection was performed using a modification of Akaike's Information Criterion (AIC) (Akaike 1973, Burnham and Anderson 1998). An extension of likelihood theory, AIC is an estimate of the relative distance between model pairs (Burnham and Anderson 1998), where distance refers to the Kullback-Leibler distance of information theory (Kullback and Leibler 1951). The Kullback-Leibler distance is a measure of the degree of information loss when a model is used to approximate reality (Cover and Thomas 1991, Burnham and Anderson 1998). Specifically, AIC is defined as

$$
\mathrm{AIC}=-2 \log (\mathrm{L})+2 k
$$

Eq. 1

where $\mathrm{L}$ is the likelihood function calculated from the maximum likelihood estimates of the model parameters and $k$ is the number of estimable parameters in the model (Buckland et al. 1997, Burnham and Anderson 1998). We used the small sample adjustment to the AIC that also corrects for overdispersion in count data, called QAICc. This statistic is calculated as

$$
\mathrm{QAICc}=\frac{-2 \log (\mathrm{L})}{\hat{\mathrm{c}}}+2 k+\frac{2 k(k+1)}{n-k-1}
$$

where $\hat{c}$ is the GOF $\chi^{2}$ statistic for the global model and $n$ is the sample size (Burnham and Anderson 1998). We used $\hat{c}$ to adjust for overdispersion in parameter estimates for each candidate model as well.

Models with lower QAICc values are considered better approximating models. However, QAICc is a relative statistic. The meaningful quantity for comparing candidate models is the difference between a particular model's QAICc value and the lowest QAICc value from all models; this difference is referred to as $\triangle$ QAICc (Burnham and Anderson 1998). The relative plausibility of each model given the data $\left(w_{i}\right)$ then can be computed as

$$
w_{i}=\frac{e^{\left(-\Delta Q \mathrm{AICc}_{i} / 2\right)}}{\sum_{i=1}^{I} e^{\left(-\Delta Q \mathrm{AICc}_{i} / 2\right)}},
$$

where $\triangle \mathrm{QAICc}_{i}$ is the $\triangle \mathrm{QAICc}$ value for the $i$ th model in a set of $I$ candidate models (Buckland et al. 1997). These $w_{i}$, or model weights, also can be used in model 
averaging. Instead of assuming a single "best" model and using its parameter estimates to make inferences, we based our inferences and predictions on a composite model generated from the $w_{i}$ weighted average of parameter estimates for each landscape covariate from the set of candidate models (see Buckland et al [1997] for a more in-depth discussion of model averaging). This composite model only contained landscape covariates that were in those candidate models whose $w_{i}$ were at least one-tenth of the maximum $w_{i}$.

\section{Interpreting Model Results}

Data for landscape covariates were standardized so that their parameter estimates could be interpreted on a common scale. Using observed parameter estimates, we computed a conditional odds ratio for each covariate to facilitate interpretation of the magnitude of its effect on observed parr densities. Conditional odds ratios were multiplied by a constant whose magnitude allowed an ecological interpretation of the unit change (Hosmer and Lemeshow 1989). For example, the conditional odds ratio for SLOPE was multiplied by 10 because we felt a $10 \%$ change in SLOPE from one subwatershed to another had more meaning than a single unit (1\%) change in SLOPE.

We did not simply rely on statistical significance to interpret model results because a conditional odds ratio could be small enough to be considered biologically unimportant but still be statistically significant (i.e., does not include 1 in the confidence interval; Yoccoz 1991). Therefore, we assessed the biological importance of each covariate in the composite model by computing $90 \%$ confidence intervals for the conditional odds ratios (see Hosmer and Lemeshow 1989:44, 57) and interpreting the magnitudes of the values contained within these intervals (Gerard et al. 1998). A confidence interval that only contained values whose sizes were considered meaningful indicated a biologically important influence of the covariate on observed parr densities. Conversely, an interval that only contained values whose magnitudes were considered of minimal importance indicated a covariate with little influence on observed parr densities. Finally, a confidence interval that contained values either on both sides of 1 or whose range included both biologically important and unimportant magnitudes indicated inconclusive results due to imprecision from inadequate sample sizes. We used SAS (SAS Institute, Inc. 1996) for all of our analyses.

\section{Results}

We used data from 1990 for steelhead and 1987 for chinook because these years contained both the highest average observed densities of parr and narrowest confidence intervals of these estimates for each species. The global model with steelhead density categories as the response variable adequately fitted the data (Hosmer and Lemeshow GOF statistic $=9.81,7 \mathrm{df}, P=0.20)$ and had no obvious outliers. After removing one obvious outlier, the global model for chinook also adequately fitted the data (Hosmer and Lemeshow GOF statistic $=6.06,7 \mathrm{df}, P=0.53$ ). 
For the steelhead parr data, the model containing mean annual precipitation (PRECIP) and percent unconsolidated lithology (UNCONSOL) was the best approximating model but was only slightly more plausible than the next highest ranked model (Table 2). The composite habitat model contained three covariates whose conditional odds ratios were statistically significant (Table 3), but only one (UNCONSOL) had a fairly strong effect on observed parr densities. That is, moderate to high observed densities of steelhead parr were at least 1.43 (1/0.701) times less likely to occur in subwatersheds with every increase in $10 \%$ unconsolidated lithology than low observed densities. Thus, there was a negative relationship between observed steelhead parr densities and unconsolidated lithology.

Both mean annual maximum summer temperature and percent mafic lithology had small positive effects on moderate to high observed densities of steelhead parr. Moderate to high steelhead parr densities were at least 1.09 times more likely to occur in subwatersheds with every increase in $2{ }^{\circ} \mathrm{C}$ mean annual maximum summer temperature, whereas parr densities were at least 1.12 times more likely to occur in subwatersheds with every increase in $10 \%$ mafic lithology (Table 3). Information on all other covariates in the composite habitat model was inconclusive.

For the chinook parr data, the candidate model containing mean annual precipitation, percent of subwatershed containing $>50 \%$ slopes, and geometric mean road density was nearly three times more plausible than the next best approximating model (Table 4). The composite habitat model for the chinook data contained three covariates that were statistically significant, two of which had at least a fairly strong effect on parr densities (Table 3). Geometric mean road density had a decidedly negative relationship with chinook parr densities in that moderate to high densities of parr were $1.78(1 / 0.562)$ times less likely to occur in subwatersheds with every increase in $2 \mathrm{~km} / \mathrm{km}^{2}$ road densities. Conversely, moderate to high densities of chinook parr were at least 1.29 times more likely to occur in subwatersheds with every $200 \mathrm{~mm}$ increase in mean annual precipitation. The lower bound of the conditional odds ratio for percent slope $>50 \%$ in a subwatershed was statistically significant, but of trivial magnitude (Table 3). Evidence was inconclusive for the remaining covariates in the chinook composite habitat model.

\section{Discussion}

Results generated from our analyses must be viewed within the limitations of the parr monitoring data set. First of all, our analyses suffered from the fact that our objective differed from the one originally set forth in the parr monitoring project. Therefore, we had to subset the data to conform to our needs. Second, problems with study design, particularly the unknown impact of bias generated from the nonrandom selection of stream sections and counts uncorrected for incomplete detectability of individuals, compelled us to further subset and pool the data. In the latter case, simply modeling raw counts with covariates thought to influence detectability of fish will not correct for sampling bias, but will only reflect how well the covariates relate to the biased counts. The matter of confounding still exists. Such a modeling approach would only be valid if: 1) the nature and magnitude of the counting bias was known for single or 
repeated counts; or 2) repeated counts were conducted on each stream section and the true abundance did not change among counts. Changes in both abundance and covariate values across repeated counts produces confounding between biased counts and covariates (K. Burnham, pers. commun.). Third, by scaling up to the subwatershed level, we had to assume that the sampled stream sections were an adequate representation of steelhead or chinook populations for all relevant stream sections (i.e., B or C channels) within their respective subwatersheds.

Within the boundaries of inference allowed by the data set, there were some patterns that emerged between density categories of steelhead and chinook and various landscape attributes. The negative influence of geometric mean road density on relative density categories of chinook should be of particular interest to land managers who are charged with ensuring the persistence of anadromous salmonid populations. Lee et al. (1997) also reported a negative influence of road densities on population status of fish species, which was based on empirical data and expert judgement, in the Columbia River Basin. These findings are notable with respect to the recent road closure policy proposed by the USDA Forest Service (Federal Register 1998b).

The fairly strong negative influence of unconsolidated lithology on observed steelhead parr densities could be related to sedimentation. An unconsolidated lithology is one that tends to slough off more than other, more consolidated lithologies, and hence would contribute more sediment inputs into surrounding streams, which could adversely affect parr survival (Crouse et al. 1981, Waters 1995). Conversely, a mafic lithology contains a strong alkaline component and hence its inputs may be tied to higher alkalinity in streams, which has been previously related to increased fish production (Scarnecchia and Bergersen 1987, Waters et al. 1993, Kwak and Waters 1997). This idea is consistent with the positive relationship between average maximum summer temperature (which was within the range of tolerance for steelhead) and observed steelhead parr densities, where elevated summer temperature may increase primary production in a stream.

The fairly strong positive influence of mean annual precipitation on relative density categories of chinook parr may be related to the positive impact that stream discharge typically has upon survival rates of anadromous salmonids (Gibson and Myers 1988, Bradford 1994, Fukushima and Smoker 1997). However, other factors related to high stream flows may be influencing chinook parr densities as well, such as lower predation rates, increased rearing habitat (Bradford 1994), and decreased egg mortality due to freezing (Gibson and Myers 1988).

Although our results cannot be properly extrapolated beyond the sites actually sampled, they do appear to support the PATH group's continued evaluation of the relative importance of freshwater rearing habitats to the persistence of anadromous salmonid populations in the Columbia River Basin. Further, despite the fact our modeling results are tentative due to the nature of the data, meaningful covariates identified in our analyses could be the starting point for any future investigations into building a predictive model for mapping approximate status and quality of rearing habitats for steelhead and chinook across relevant areas in Idaho (e.g., Bradford et al. 
1997, Lee et al. 1997). Such a model could be updated and refined as more and better information became available.

\section{Acknowledgments}

R. King, M. Jones, C. Paulsen, and C. Petrosky provided helpful comments on an earlier draft of this manuscript. We thank J. Hall-Griswold and C. Petrosky of the Idaho Fish and Game Department for allowing us access to the parr monitoring data set as well as providing background on the parr monitoring project. J. Peterson conducted preliminary, descriptive analysis of the data set and offered helpful suggestions for its more detailed analysis. This work was funded by the Bonneville Power Administration under Project 92-32.

\section{References}

Akaike, H. 1973. Information theory and an extension of the maximum likelihood principle. Pages 267-281 in B. N. Petrov and F. Csaki, eds. Second International Symposium on Information Theory. Akademiai Kiado, Budapest.

Bisson, P. A., T. P. Quinn, G. H. Reeves, and S. V. Gregory. 1992. Best management practices, cumulative effects, and long-term trends in fish abundance in Pacific Northwest river systems. Pages 189-232 in R. J. Naiman, editor. Watershed management: balancing sustainability. Springer-Verlag, New York.

Bradford, M. J. 1994. Trends in the abundance of chinook (Oncorhynchus tshawytscha) of the Nechako River, British Columbia. Can. J. Fish. Aquat. Sci. 51:965-973.

Bradford, M. J., G. C. Taylor, and J. A. Allan. 1997. Empirical review of coho salmon smolt abundance and the prediction of smolt production at the regional level. Trans. Am. Fish. Soc. 126:49-64.

Buckland, S. T., K. P. Burnham, and N. H. Augustin. 1997. Model selection: an integral part of inference. Biometrics 53:603-618.

Burnham, K. P., and D. R. Anderson. 1998. Model selection and inference: a practical information theoretic approach. Springer-Verlag, New York.

Cover, T. M., and J. A. Thomas. 1991. Elements of information theory. John Wiley, New York.

Crouse, M. R., C. A. Callahan, K. W. Malueg, and S. E. Dominguez. 1981. Effects of fine sediments on growth of juvenile coho salmon in laboratory streams. Trans. Am. Fish. Soc. 110:281-286. 
Daly, C., R. P. Neilson, and D. L. Phillips. 1994. A statistical-topographic model for mapping climatological precipitation over mountainous terrain. J. Appl. Meteor. 33:140-158.

Federal Register. 1997. Endangered and threatened species: listing of several evolutionary significant units (ESUs) of west coast steelhead. Federal Register 62(159):43937-43954.

Federal Register. 1998a. Endangered and threatened species: withdrawal of proposed rule to list Snake River spring/summer chinook and fall chinook salmon as endangered. Federal Register 63(7):1807-1811.

Federal Register. 1998b. Administration of the forest development transportation system. Federal Register 63(18):4350-4351.

Fukushima, M., and W. W. Smoker. 1997. Determinants of stream life, spawning efficiency, and spawning habitat in pink salmon in the Auke Lake system. Can. J. Fish. Aquat. Sci. 54:96-104.

Gerard, P. D., D. R. Smith, and G. Weerakkody. 1998. Limits of retrospective power analysis. J. Wildl. Manage. 62:801-807.

Hall-Griswold, J. A., and C. E. Petrosky. 1996. Idaho habitat/natural production monitoring, part 1. U.S. Dept. Energy Bonneville Power Admin. Ann. Report 1995, Project 91-73. Available on the Internet at http://www.efw.bpa.gov/Environment/EW/EWP/DOCS/REPORTS/HABITAT/w ithpdf.htm

Hosmer, D. W., Jr., and S. Lemeshow. 1989. Applied logistic regression. J. Wiley, New York.

Johnson, S. W., J. Heifertz, and K. V. Koski. 1986. Effects of logging on the abundance and seasonal distribution of juvenile steelhead in some southeastern Alask streams. N. Am. J. Fish. Manage. 6:532-537.

Kullback, S., and R. A. Leibler. 1951. On information and sufficiency. Ann. Math. Stat. 22:79-86.

Kwak, T. J., and T. F. Waters. 1997. Trout production dynamics and water quality in Minnesota streams. Trans. Am. Fish. Soc. 126:35-48.

Lee, D. C., and W. E. Grant. 1995. A hierarchical approach to fisheries planning and modeling in the Columbia River Basin. Environ. Manage. 19:17-25.

Lee, D. C., J. R. Sedell, B. E. Rieman, R. F. Thurow, J. E. Williams, D. Burns, J. Clayton, L. Decker, R. Gresswell, R. House, P. Howell, K. M. Lee, K. 
Macdonald, J. McIntyre, S. McKinney, T. Noel, J. E. O’Connor, C. K. Overton, D. Perkinson, K. Tu, and P. Van Eimeren. 1997. Broadscale assessment of aquatic species and habitats. Pages 1057-1713 in T. M. Quigley and S. J. Arbelbide, tech. eds. An assessment of ecosystem components in the Interior Columbia Basin and portions of the Klamath and Great Basins. Volume III. U.S.D.A. For. Serv., Gen. Tech. Rep. PNW-GTR-405, Portland.

Marmorek, D. R., and C. N. Peters, eds. 1998. Plan for analyzing and testing hypotheses (PATH): retrospective and prospective analyses of spring/summer chinook reviewed in FY 1997. Compiled and edited by ESSA Technologies, Ltd, Vancouver, British Columbia. Available on the Internet at http://www.efw.bpa.gov/Environment/PATH/

National Research Council. 1996. Upstream: salmon and society in the Pacific Northwest. National Research Council, Washington, D.C. Chapter 3:39-66.

Nehlsen, W., J. E. Williams, and J. A. Lichatowich. 1991. Pacific salmon at the crossroads: stocks at risk from California, Oregon, Washington, and Idaho. Fisheries 16(2):4-21.

Northwest Power Planning Council. 1986. Compilation of information on salmon and steelhead losses in the Columbia River Basin. Northwest Power Planning Council, Portland.

Petrosky, C. E., and T. B. Holubetz. 1986. Idaho habitat evaluation for off-site mitigation record. U. S. Dept. Energy Bonneville Power Admin. Ann. Rep. 1985, Proj. 83-7.

Rich, B. A., and C. E. Petrosky. 1994. Idaho habitat and natural production monitoring: part 1. U. S. Dept. Energy Bonneville Power Admin. Ann. Rep. 1992, Proj. 91-73.

Roper, B. B., D. L. Scarnecchia, and T. J. La Marr. 1994. Summer distribution of and habitat use by chinook salmon and steelhead within a major basin of the South Umpqua River, Oregon. Trans. Am. Fish. Soc. 123:298-308.

Rosgen, D. L. 1985. A stream classification system. North American Riparian Conference, Tucson, Arizona, April 16-18, 1985.

SAS Institute, Inc. 1996. SAS/STAT software: changes and enhancements, through version 6.11. SAS Institute Inc., Cary.

Scarnecchia, D. L., and E. P. Bergersen. 1987. Trout production and standing crop in Colorado's small streams, as related to environmental features. N. Am. J. Fish. Manage. 7:315-330. 
Schlosser, I. J. 1991. Stream fish ecology: a landscape perspective. Bioscience 41:704712.

Thompson, W. L., G. C. White, and C. Gowan. 1998. Monitoring vertebrate populations. Academic Press, San Diego.

Thurow, R. F. 1994. Underwater methods for study of salmonids in the Intermountain West. U.S.D.A. For. Serv. Gen. Tech. Rep. INT-GTR-307, Ogden.

Waters, T. F. 1995. Sediment in streams: Sources, biological effects and control. Am. Fish. Soc. Monogr. No. 7, Bethesda.

Waters, T. F., J. P. Kaehler, J. T. Polomis, and T. J. Kwak. 1993. Production dynamics of smallmouth bass in a small Minnesota stream. Trans. Am. Fish. Soc. 122:588598.

Yoccoz, N. G. 1991. Use, overuse, and misuse of significance tests in evolutionary biology and ecology. Bull. Ecol. Soc. Am. 72:106-111. 
Table 1. Category and description of covariates used in modeling landscape habitat characteristics (Lee et al. 1997) with relative density categories of steelhead and chinook parr. Habitat characteristics are at the subwatershed (HUC6) spatial scale (see description in text).

\begin{tabular}{|c|c|c|}
\hline Category & Model Covariate & Description \\
\hline \multirow[t]{5}{*}{$\begin{array}{l}\text { Physiographic and } \\
\text { Geophysical }\end{array}$} & Precip & $\begin{array}{l}\text { Mean annual precipitation (mm) based on the } \\
\text { PRISM model (Daly et al. 1994) }\end{array}$ \\
\hline & Sumtemp & Mean annual maximum summer temperature $\left({ }^{\circ} \mathrm{C}\right)$ \\
\hline & Slope & Percent $(\%)$ of HUC6 with slopes $>50 \%$ \\
\hline & Mafic & Percent $(\%)$ of HUC6 with mafic lithology \\
\hline & Unconsol & Percent (\%) of HUC6 with unconsolidated lithology \\
\hline \multirow[t]{6}{*}{ Anthropogenic } & Georoad & Geometric mean road density $\left(\mathrm{km} / \mathrm{km}^{2}\right)$ \\
\hline & Mngclus & $\begin{array}{l}\text { Management cluster variable containing four land- } \\
\text { use categories: }\end{array}$ \\
\hline & & $\begin{array}{l}\text { 1) HIF (high impact forest) - high impact, grazed } \\
\text { USDA Forest Service forest }\end{array}$ \\
\hline & & $\begin{array}{l}\text { 2) MF (managed forest) - moderate to high impact, } \\
\text { ungrazed USDA Forest Service forest }\end{array}$ \\
\hline & & $\begin{array}{l}\text { 3) W (wilderness) - USDA Forest Service } \\
\text { wilderness }\end{array}$ \\
\hline & & $\begin{array}{l}\text { 4) } \mathrm{R} \text { (rangeland) - USDI BLM rangelands and } \\
\text { moderate impact, grazed USDA Forest Service } \\
\text { rangeland }\end{array}$ \\
\hline
\end{tabular}


Table 2. Model selection results for logistic regression models containing landscape habitat predictor variables and relative density response categories of steelhead parr sampled during 1990 ( $\underline{\mathrm{n}}=79$ HUC6s [155 stream sections]).

\begin{tabular}{|c|c|c|c|c|}
\hline Candidate Model & OAICc & $\triangle \mathrm{OAICc}$ & $\begin{array}{l}\triangle \mathrm{QAICc} \\
\text { Weight }\end{array}$ & $\%$ of Maximum \\
\hline Precip, Unconsol & 81.51 & 0 & 0.280 & 100 \\
\hline Precip, Mafic & 82.10 & 0.59 & 0.208 & 74.3 \\
\hline Precip, Slope, Unconsol & 82.96 & 1.45 & 0.136 & 48.6 \\
\hline Sumtemp, Mafic & 83.23 & 1.72 & 0.119 & 42.5 \\
\hline Precip, Slope, Mafic & 84.28 & 2.77 & 0.070 & 25.0 \\
\hline \multicolumn{5}{|l|}{ Precip, Slope, Unconsol, } \\
\hline Georoad & 84.90 & 3.39 & 0.051 & 18.2 \\
\hline Unconsol, Georoad, Mngclus & 85.76 & 4.25 & 0.034 & 12.1 \\
\hline Slope, Mafic & 85.82 & 4.31 & 0.033 & 11.8 \\
\hline Sumtemp & 86.39 & 4.88 & 0.024 & 8.6 \\
\hline Georoad & 87.05 & 5.54 & 0.018 & 6.4 \\
\hline Precip & 88.30 & 6.79 & 0.009 & 3.2 \\
\hline Global Model & 88.58 & 7.07 & 0.008 & 2.9 \\
\hline Precip, Slope, Georoad & 89.44 & 7.93 & 0.005 & 1.8 \\
\hline Mngclus & 91.89 & 10.38 & 0.002 & 0.7 \\
\hline Georoad, Mngclus & 92.76 & 11.25 & 0.001 & 0.4 \\
\hline Slope, Mngclus & 94.13 & 12.62 & $<0.001$ & 0.2 \\
\hline Sumtemp, Mngclus & 94.73 & 13.22 & $<0.001$ & 0.1 \\
\hline
\end{tabular}


Table 4. Model selection results for logistic regression models containing landscape habitat predictor variables and relative density response categories of chinook parr sampled during 1987 ( $\underline{\mathrm{n}}=37$ HUC6s $[72$ stream sections]).

$\triangle \mathrm{QAICc} \quad \%$ of Maximum

\begin{tabular}{lcccc} 
Candidate Model & QAICc & $\triangle$ QAICc & Weight & $\triangle$ QAICc Weight \\
\hline Precip, Slope, Georoad & 46.50 & 0 & 0.379 & 100 \\
Precip, Mafic & 48.48 & 1.98 & 0.141 & 37.2 \\
Precip & 48.77 & 2.27 & 0.122 & 32.2 \\
Precip, Slope, Mafic & 49.15 & 2.65 & 0.101 & 26.6 \\
Precip, Slope, Unconsol, Georoad & 49.16 & 2.66 & 0.101 & 26.6 \\
Precip, Unconsol & 50.07 & 3.57 & 0.064 & 16.9 \\
Georoad & 51.72 & 5.22 & 0.028 & 7.4 \\
Precip, Slope, Unconsol & 51.98 & 5.48 & 0.024 & 6.3 \\
Sumtemp & 53.50 & 7.00 & 0.011 & 2.9 \\
Slope, Mafic & 53.87 & 7.37 & 0.010 & 2.6 \\
Sumtemp, Mafic & 54.19 & 7.69 & 0.008 & 2.1 \\
Global Model & 54.94 & 8.44 & 0.006 & 1.6 \\
Slope, Georoad, Mngclus & 56.87 & 10.37 & 0.002 & 0.5 \\
Mngclus & 58.05 & 11.55 & 0.001 & 0.3 \\
Slope, Mngclus & 58.44 & 11.94 & 0.001 & 0.3 \\
Georoad, Mngclus & 58.60 & 12.10 & 0.001 & 0.3 \\
Unconsol, Georoad, Mngclus & 61.42 & 14.92 & $<0.001$ & $<0.1$ \\
\hline
\end{tabular}

